\title{
Hemimegalencephaly: foetal tauopathy with mTOR hyperactivation and neuronal lipidosis
}

\author{
Harvey Sarnat', Laura Flores-Sarnat', Peter Crino², Walter Hader ${ }^{1}$, Luis Bello-Espinosa ${ }^{1}$ \\ 1University of Calgary and Alberta Children's Hospital Calgary, Alberta, Canada, 2University of Pennsylvania, Philadelphia, Pennsylvania, USA
}

\begin{abstract}
Background: Hemimegalencephaly (HME) is a hamartomatous malformation of one cerebral hemisphere. As this is a disorder of cellular growth and lineage, we sought evidence of an early ontogenetic disturbance of microtubular assembly or function.

Material and methods: Three male infants with HME had brain resections for refractory epilepsy. One died postoperatively at 2.5 months and an autopsy was performed. Two were isolated cases and one has Proteus syndrome. The phosphorylated form of the microtubule-associated protein tau was studied, transmission electron microscopy (EM) was performed, and activation of the MTOR pathway was defined.

Results: The hippocampus and neocortex of HME exhibited cytoarchitectural abnormalities and intense tau immunoreactivity. The post-mortem non-HME hemisphere exhibited sparse dysmorphic tau-reactive cortical neurones, intense only in the cingulate gyrus, a few isolated dysmorphic white matter neurons and none in subcortical structures. Numerous enlarged and dysmorphic cells exhibited P-4E-BP1 and phosphoribosomal P-S6 immunoreactivity, indicating mTOR activation. Control brains were negative for tau expression and mTOR activation. EM in each case showed abundant lipid in neurones and astrocytic end-feet on capillaries, and well-preserved mitochondria; oil red $O$ in frozen sections and semi-thin sections also showed lipid storage by light microscopy.

Conclusions: Because HME tissue exhibited enhanced levels of phosphorylated tau protein and evidence of mTOR hyperactivation, we propose that the pathogenesis of HME may involve an early defect in microtubules, likely related to the AKT3 gene. Lipidosis of neurones and glia suggests metabolic impairment of yet undetermined type and relation to tauopathy in HME. Perinatal treatment of HME with everolimus theoretically is plausible.
\end{abstract}

Key words: hemimegalencephaly, tauopathy, mTOR, lipidosis, malformation.

\section{Introduction}

Hemimegalencephaly (HME) is a malformation of one cerebral hemisphere that presents graded severity and morphology, also involving the ipsilateral brainstem and cerebellum in a minority of cases $[15,16]$. As a hamartomatous dysgenesis, not only tissue archi- tecture but also cellular growth, proliferation, cytomorphology and lineage are abnormal $[18,44,48]$ as well as synaptogenesis [36]. Though it shares some neuropathological features with cortical tubers in tuberous sclerosis complex and also involves defects in the mTOR signalling pathway, it is not due to defective TSC1 
or TSC2 genes, but several cases of HME in tuberous sclerosis are documented [2,16,19]. Nor does HME follow a Mendelian trait. Aetiology and pathogenetic mechanisms remain unknown. It may be isolated or associated with other neurocutaneous syndromes, particularly epidermal nevus and Proteus syndromes $[15,16]$. Severe HME is one of the most epileptogenic congenital malformations of the cerebral cortex.

Microtubules are expressed early in neuroepithelial cells and determine cellular polarity, contribute to the cytoskeleton including the formation of neurites and axonal growth cones, provide for axonal transport of many molecules essential to cellular migration. The transcription products of many genes that are defective in primary neuroblast migratory disorders are microtubule-associated proteins (MAPs), for example $D C X$ and $A R X$. Tau protein is another MAP expressed in its natural form at low levels throughout the brain during foetal life. Up-regulation of an abnormal phosphorylated tau protein is a characteristic finding in several adult-onset neurodegenerative diseases, such as fronto-temporal lobar degeneration, cortico-basal degeneration, Alzheimer disease and Parkinson disease [32]. Tau over-expression, neither the natural nor the phosphorylated forms, is not a known feature of any developmental disorder during ontogenesis or in infancy or childhood, including many hereditary neurodegenerative and metabolic encephalopathies of early life, though possibly because it has previously not been studied. Nevertheless, amongst genetically programmed malformations of the brain, abnormal microtubular dynamics occur with mutations in genes that cause lissencephaly type 2 [31] and Joubert syndrome [12], but tau over-expression has not been reported.

In our survey of microtubule-associated proteins in $\mathrm{HME}$, we present evidence from three cases that phosphorylated tau protein is over-expressed within the hamartomatous tissue.

\section{Material}

\section{Case 1}

This preterm male infant, born at 35 weeks, was diagnosed with severe left hemimegalencephaly by MRI (Fig. 1A) after presenting with neonatal seizures on day 1 . He underwent corpus callosotomy at 3 weeks with a small biopsy of the non-HME right cingulate gyrus. Partial resection of the $L$ temporal and frontal lobes was performed at 2.5 months of age because of pharmacologically intractable epilepsy. He died of complications, including disseminated intravascular coagulation, the morning following surgery; autopsy (restricted to brain) was performed within a few hours after death. Genetic studies of the AKT1 and AKT3 genes are in progress.

\section{Case 2}

This male infant was born at 37 weeks gestation with a prenatal diagnosis of severe left hemimegalencephaly by foetal MRI at 32 weeks (Fig. 1B). Though clinical seizures did not appear until a month of age, antiepileptic treatment was started on the first postnatal day because of a paroxysmally abnormal EEG and an expectation of a high risk of seizures. Pigmented linear lesions of the neck became evident at age 3-4 months. Epidermal naevus syndrome was suspected and overgrowth of the left index finger first noted from age 9 months first posed a question of Proteus syndrome. Ophthalmological examination also disclosed several ocular features characteristic in the Proteus syndrome and he has developed several other overgrowths and defective dentition that further confirmed this diagnosis. Epilepsy worsened and he underwent left partial hemispherectomy, including temporal neocortex but not hippocampus, at age 8 months. Because of persistent seizures associated with an epileptic focus in the left frontal lobe at age 18 months, further resection was performed of the remaining cortical tissue. Now at 28 months of age, seizures are better controlled and he is making slow progress in development. Genetic studies of the AKT1 (Proteus syndrome) and AKT3 (hemimegalencephaly) genes are in progress.

\section{Case 3}

This male infant was delivered at term after an unremarkable pregnancy. At 10 days of age he developed partial seizures and flexor spasms that evolved to Ohtahara syndrome with a burst-suppression EEG pattern more severe on the right. MRI of the brain revealed right HME with pachygyria and enlarged white matter in the frontal lobe; the right frontal horn of the lateral ventricle was enlarged, as seen in axial (Fig. 1C) and coronal (Fig. 1D) planes. He had mild left hemiparesis and reflex preponderance on that side. Because of refractory seizures, partial right fronto-temporal resection was performed at age $21 / 2$ years with subsequent improvement of seizures. Development was always delayed and he was diagnosed with "autistic spectrum disorder". He is now $81 / 2$ years old. 

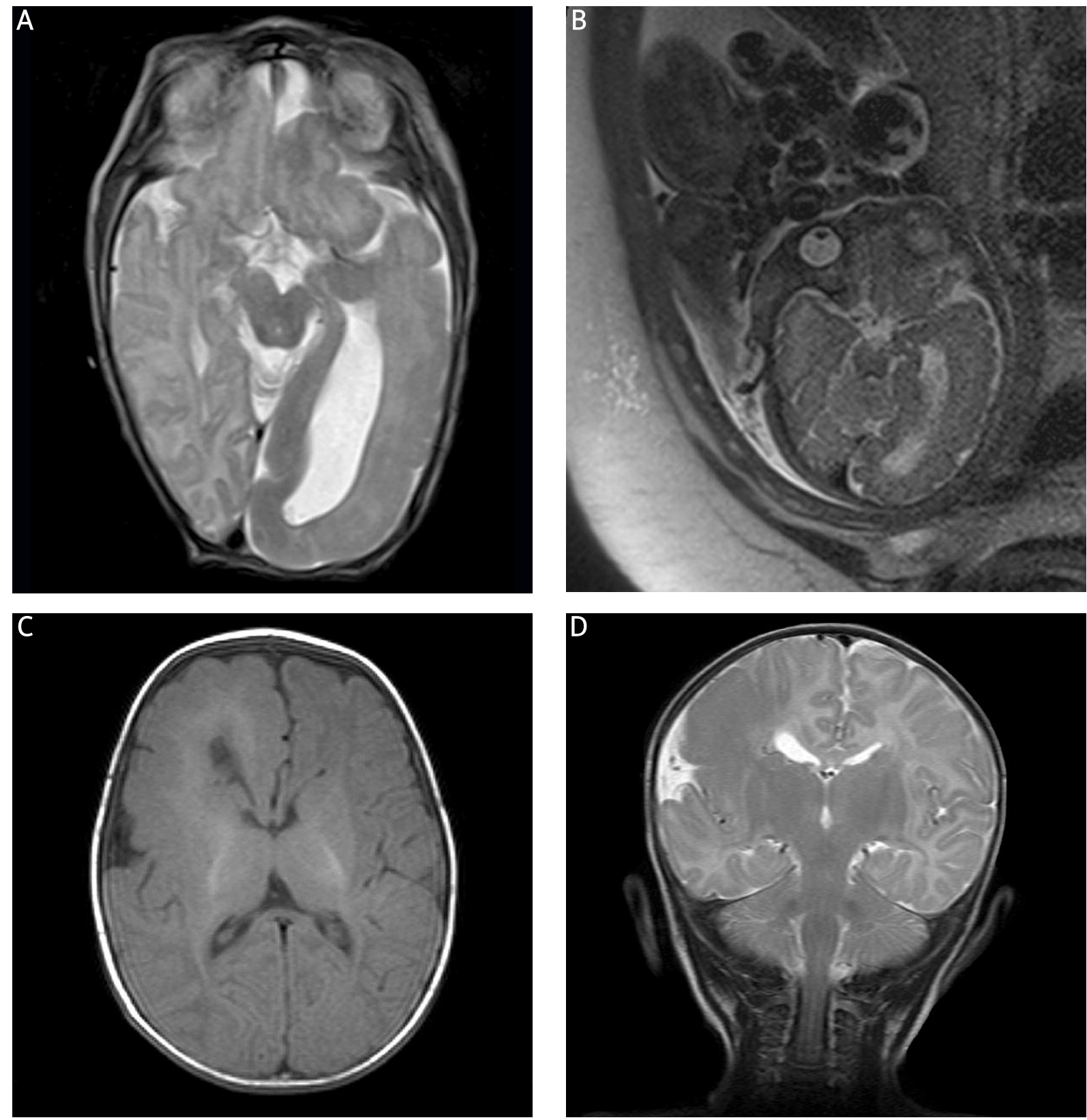

Fig. 1. T-2 weighted axial MRI of (A) Case 1, pre-operatively at 2 months of age, and (B) Case 2, intrauterine foetal MRI at 32 weeks gestation. Both exhibit left hemimegalencephaly with ipsilateral colpocephaly. C, D) Case 3 at 2 years of age. T-1 weighted (C) axial and (D) coronal views of right hemimegalencephaly. The right frontal cortex is pachygyric/lissencephalic; the right frontal horn is straightened and mildly dilated. A, B): courtesy of Dr Xing-Chang Wei, Dept. of Radiology and Diagnostic Imaging, Alberta Children's Hospital; C, D): courtesy of Dr S. Haider and Dr J.N. Scott, Dept. of Radiology and Diagnostic Imaging, Alberta Children's Hospital and Foothills Provincial Regional Hospital, Calgary).

\section{Patient consent}

This study complied fully with the ethical guidelines of the University of Calgary and Alberta Health Serv- ices. Parents signed consents for surgical procedures that explicitly included pathological examination of tissue resected. Because the antibodies used for immunocytochemistry were all standard and commercially avail- 
able, and none were experimental, and because the results here described were included in the neuropathology report, special permission from the Ethics Committee was not needed, including in the judgment of the chair of that Committee. Permission for autopsy was secured in Case 1 from the parents, that permitted all neuropathological investigations performed.

\section{Methods}

Tau protein, mouse monoclonal antibody (MN1020, Thermo Scientific, Rochester, Illinois, USA), was applied at $1: 100$ dilution; it recognizes a phosphatase-sensitive epitope on PHF-tau without cross-reactivity with normal tau. The epitope of this antibody contains the phosphorylated Ser202 $(5,33)$ residue (numbering according to human tau-40).

In addition to the tau protein, we also examined immunoreactivity for ubiquitin, $\alpha$-synuclein and TDP-45. The reason for studying these proteins is that they may be co-expressed in some adult neurodegenerative tauopathies. Neuronal nuclear antigen (NeuN; 1 : 40 dilution; Chemicon-Millipore, Temecula, California, USA), neuron-specific enolase (NSE; 1 : 500 dilution; DakoCytomation, Copenhagen, Denmark), neurofilament protein (NFP; 1 : 4000 dilution, Biogenex, San Ramon, California, USA) and microtubule-associated protein-2 (MAP2; 2a,b mouse monoclonal antibody MS-249-S0, clone AP20, Thermo Scientific) were applied as neuronal markers; vimentin (1 : 400 dilution; DakoCytomation) and glial fibrillary acidic protein (GFAP, monoclonal antibody at $1: 1000$ dilution and polyclonal antibody, 1 : 4000 dilution; DakoCytomation) served as glial markers. CD-68 was used as a marker of microglial activation. Alpha-B-crystallin immunoreactivity was used as a tissue marker of epileptic foci (Covance: Emeryville, California, USA; polyclonal LAP-70 carboxy-terminus antibody against peptide of the last 14 amino acids; host: rabbit; 1 : 50 dilution incubated at $37^{\circ} \mathrm{C}$ ) [41]. Bielschowsky silver impregnations were made. Immunostaining was scored qualitatively as intense, moderate, weak or absent.

Protein markers of mTOR activation were defined in Cases 1 and 2 by immunohistochemical detection of phospho-protein isoforms including P-p70S6K1 (Thr389; cell signalling), P-S6 (Ser235/236; cell signalling) or phospho-4E-BP-1 (cell signalling) overnight at $4^{\circ} \mathrm{C}$. Immunoreactivity was visualized with avidin-biotin complex (Vectastain ABC Kit; Vector Laboratories) and 3,3'-diaminobenzidine (Sigma-Aldrich).
Sections of unfixed temporal neocortex and hippocampus were freshly frozen and $4 \mu \mathrm{m}$ sections prepared for staining with mitochondrial oxidative enzymes, reported separately as part of another study [42]. Oil red O stain for neutral lipids was also applied to these frozen sections.

Transmission electron microscopy (EM) was performed from samples of the surgical tissue in all three cases. Tissue was fixed in $2.5 \%$ glutaraldehyde, postfixed in osmium tetroxide and embedded in epoxy resin. Semi-thin $1 \mu \mathrm{m}$ sections were stained with toluidine blue for light microscopy and thin sections were stained with uranyl acetate and lead citrate for EM. Examination was performed using a Hitachi Transmission Electron Microscope, Model H7650, at magnifications of 3000x to $60000 \times$ and selected digital photomicrographs were taken.

\section{Controls}

Controls of tau immunoreactivity were provided by an adult case of tauopathy (fronto-temporal lobar degeneration), 20 normal human foetal brains, ranging from 9 to 41 weeks gestation and 4 normal infant brains of 2-24 months of age. None had post-mortem autolysis.

\section{Application to other malformations}

The present study was not designed to be a systematic survey of tau expression in cerebral malformations in general or in congenital metabolic encephalopathies, but to ensure that the findings of tau over-expression were not a non-specific feature of most malformations, the same technique for tau immunoreactivity was applied to several available foetal and infant brains with a variety of malformations: cortical tubers in tuberous sclerosis; holoprosencephaly; type 2 lissencephaly; Meckel-Grüber syndrome; schizencephaly; callosal agenesis; primary micrencephaly; and anencephaly. A case of Alpers disease and two other brains of infantile mitochondrial encephalomyopathies were also examined.

\section{Results}

\section{General neuropathological findings in $\mathrm{HME}$ cases}

The histopathological features in the hemimegalencephalic hemisphere were similar in all three cases and to other cases previously described by us and 
by other authors $[18,26,44,48]$. Gyral formation of the cortex was abnormal, corresponding in various regions to pachygyria, polymicrogyria and pseudogyri (i.e. adjacent gyri with fused molecular zones with lack of pial membranes and intervening leptomeninges, so that a sulcus is not formed); trans-pial pedunculated glioneuronal heterotopia and excessive heterotopic neurones in white matter were also demonstrated. Histologically, the malformation was hamartomatous because of both disorganized tissue architecture and cytological dysmorphism of many cells, including megalocytic atypical neurones and scattered balloon cells. Some of the dysplastic cells co-expressed both neuronal and glial markers indicative of mixed cellular lineage, such as neurofilament protein and glial fibrillary acidic protein. Bielschowsky silver revealed impregnations of compacted neurofilaments in the somata of scattered neurones, mainly pyramidal neurones, that resembled neurofibrillary tangles, and neurofilament protein was strongly immunoreactive in these neurones. Many of these cells expressed tau, but they were scattered in the deep cortical layers and the main tau gradient was in superficial layers (see below).

Myelination of white matter was less than expected for age with luxol fast blue stain, including in the brainstem longitudinal tracts in the autopsy of Case 1 and the internal capsule of all. CD-68 revealed no generalized microglial activation. $\alpha$-B-crystallin showed strong reactivity in many glial cells, including satellite cells adherent to neurones and also within some neurones themselves, in both grey and white matter, as seen at chronic epileptic foci generally.

In Case 1, the hippocampus of the HME hemisphere had well-formed general architecture, but the granular layer of the dentate gyrus was not uniform in thickness, in places showing an excess and in others a reduction in neuronal density. Granule cells showed strong reactivity for neuronal markers, including neuronal nuclear antigen (NeuN), neurone-specific enolase (NSE) and microtubule associated protein-2 (MAP2; Fig. 2A). Mixed with the granule cells and on either side of the dentate gyrus, a large number of smaller spindle-shaped cells were present. This population showed strong immunoreactivity for vimentin, nestin and CD-34, identifying these small cells as resident stem cells or pluripotential neuroepithelial precursors of neurons and glia. Pyramidal neurons of Ammon's horn were generally preserved but many were disoriented. Myelination of the alveus and fim- bria was normal. The resections of Cases 2 and 3 did not include hippocampus.

\section{Post-mortem findings in case 1}

The remaining HME tissue of the left hemisphere was similar to the surgical resection. In the right cerebral hemisphere, the architecture was generally well preserved, but a proliferation of granular neurons was found at the apex of the dentate gyrus. Rare scattered dysmorphic neurones were demonstrated in the neocortex and subcortical white matter. Subcortical structures, including basal ganglia, thalamus, hypothalamus, brainstem, cerebellum and upper cervical spinal cord revealed no dysmorphic cells or malformations. By contrast, the surgical biopsy of the right cingulate gyrus at age 3 weeks showed an excessively columnar radial architecture with superimposed horizontal lamination corresponding to focal cortical dysplasia type la, reconfirmed at autopsy.

\section{Tau in $\mathrm{HME}$}

In surgical tissue of all three cases, diffuse tau overexpression was demonstrated in the neuropil of the cerebral cortex and hippocampus (Figs. 2-4). It was also seen in the trans-pial glioneuronal heterotopia and in many subcortical heterotopic neurons (Figs. 4A, E). Reactivity was mainly in neurons rather than glial cells and was also diffusely upregulated in the neuropil, within neural processes. The molecular zone of the neocortex was strongly reactive and many cortical neurons of layers 2 and 3, but not all, were reactive (Figs. 3A, 4A-C, 5). A superficial to deep gradient thus was seen in the cerebral cortex, but scattered pyramidal neurons of deep layers also exhibited tau reactivity. The strongest and most specific neuronal reactivity was cytoplasmic; some neurons appeared to show nuclear reactivity as well, but this was regarded as non-specific and a pattern could not be recognized. Thick axons coursing centripetally in the white matter and deep and middle layers of the cortex were strongly reactive (Figs. 3A, B, $4 \mathrm{D})$, as were heterotopic white matter neurons. In the hippocampus, nearly all of the molecular neurons of the dentate gyrus and pyramidal neurones of Ammon's horn were reactive, and the clusters of neuroepithelial stem cells around the dentate gyrus also showed reactivity. White matter, including the alveus and fimbria, were also strongly reactive.

In Case 1, biopsy of the right (non-HME) cingulate gyrus exhibited strong tau immunoreactivity, but dif- 

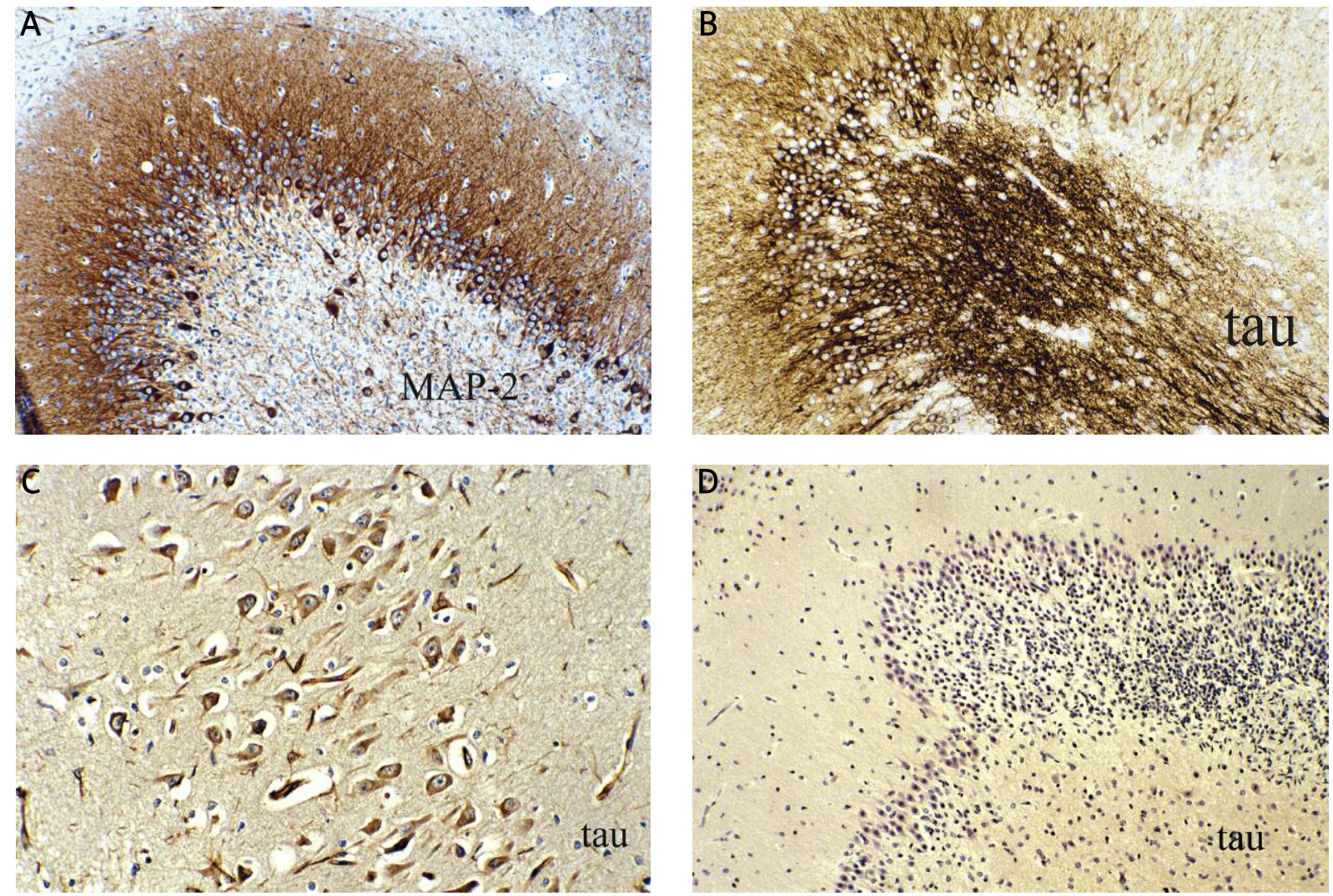

Fig. 2. Case 1. Surgical resection at age 2.5 months of the left temporal lobe of hemimegalencephalic hemisphere: (A) dentate gyrus of hippocampus showing normal expression of microtubule-associated protein2A, B (MAP2) in granular neurones; (B) intense phosphorylated tau immunoreactivity in granular neurones and surrounding neuropil. C) Tau-reactive neurons in CA2 sector of Ammon's horn in hemimegalencephalic hippocampus, but little reactivity in neuropil; (D) non-hemimegalencephalic right dentate gyrus at autopsy demonstrates mild proliferation of granular neurones at the apex, but lack of tau reactivity. Original magnifications $(A, B, D) \times 100 ;(C) \times 250$.

fered from the left HME neocortex because the molecular zone was nonreactive, except for the somata of scattered neurons, and the most intense reactivity was in the middle and deep layers, mostly in the neuropil and in coarse radial axons, as well as in some, but not all, cortical neurones, including those of layer 2 (Fig. 3D).

In the autopsy tissue of Case 1, the right (non-HME) cerebral hemisphere showed no reactivity except for a few scattered dysmorphic neurons in the cortex or white matter that were strongly tau-reactive (Fig. 3C). The exception was the cingulate gyrus, where reactivity was seen and was less intense than in the previous surgical biopsy but nevertheless of the same character. Deeper telencephalic and diencephalic structures showed no reactive cells and no reactivity was seen in periventricular regions or in ependymal cells. The brainstem, including the locus coeruleus, cerebellum and upper cervical spinal cord were also negative. The right olfactory bulb showed no tau expression; the left olfactory bulb and sulcus (HME side) could not be identified, probably agenesis. Ciliated ependymal cells were nonreactive. Residual HME tissue of the left hemisphere showed phosphorylated tau over-expression, though not as intense as the fresh surgical brain tissue.

Immunoreactivities for $\alpha$-synuclein, ubiquitin and TDP-43 were negative in sections of the same blocks in both cases that showed tau over-expression in surgical tissue. The $\alpha$-B-crystallin expression was strong in nearly all white matter glial cells, satellite glia of the grey matter and in balloon cells. None of the brains of control foetuses or infants exhibited tau reactivity using the same antibodies and techniques as the study cases. 

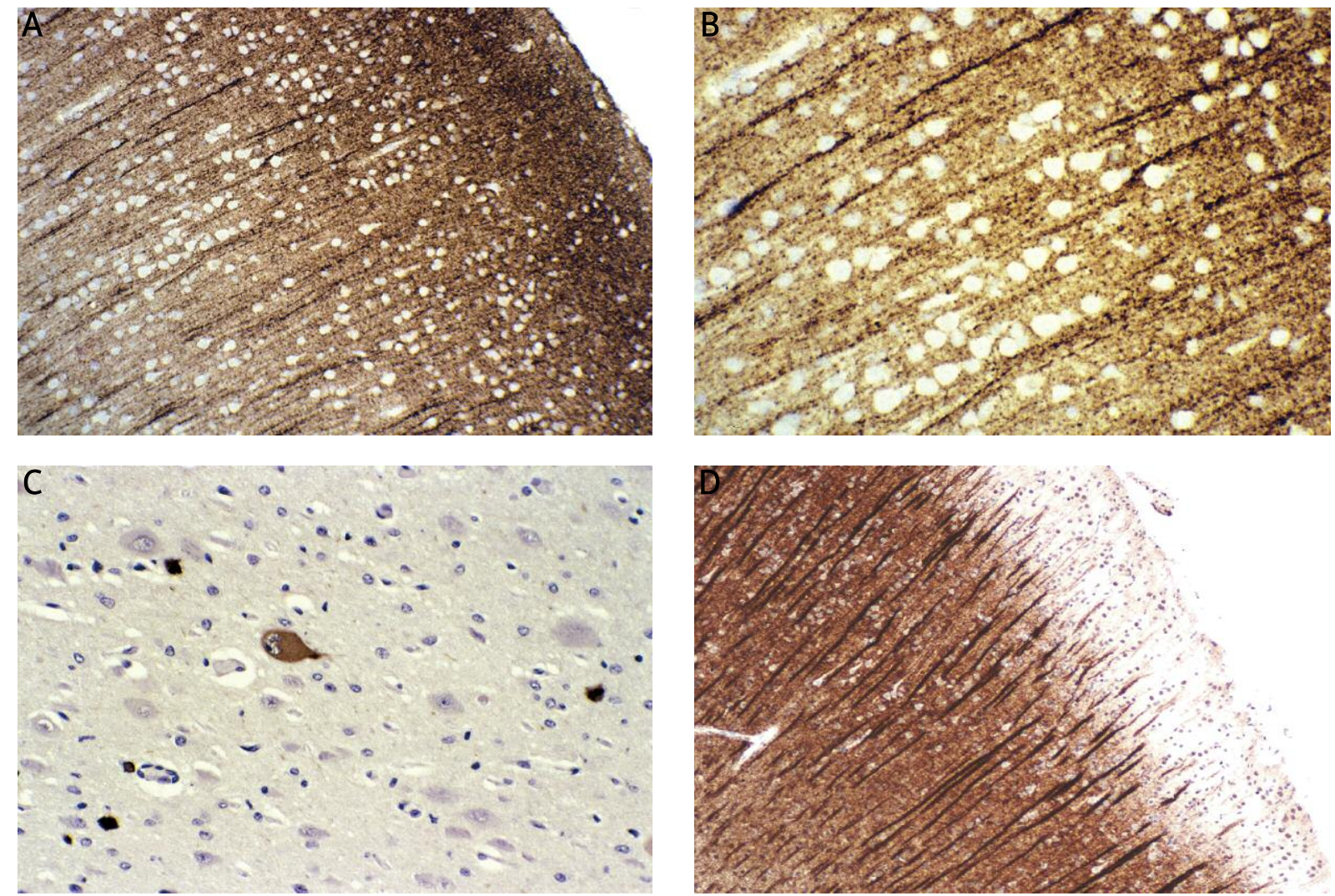

Fig. 3. Case 1. Temporal neocortex of left hemimegalencephalic hemisphere showing (A) intense tau reactivity in layers 1 and 2; deeper layers of cortex show strong reactivity in axons, but most neuronal somata are nonreactive. B) Temporal deep cortical layers of the left hemisphere, surgically resected, showing intense, beaded reactivity in coarse axons. Clusters and columns of neurones are nonreactive. The coarse axons and heterotopic neurones in the subcortical white matter were similar. C) Only rare scattered dysmorphic neocortical neurones of the right non-hemimegalencephalic hemisphere exhibit tau reactivity at autopsy, but surrounding neurones with more normal morphology do not express tau. D) An exception is the cingulate gyrus which, in this surgical biopsy at age 3 weeks, shows strong tau reactivity, but the distribution differs from the HME neocortex because the most intense reactivity is in the neuropil and radial coarse axons in middle and deep layers, with almost no reactivity in the molecular zone or in neuronal somata (contrast with Fig. 3A). The number of neurones in the molecular zone is excessive and many of them have reactive somatic cytoplasm. A-D) Tau immunoreactivity. Original magnifications (A, D) $\times 100 ;(B, C) \times 250$.

None of the controls exhibited tau reactivity in grey or white matter.

Light microscopic evidence of lipid storage in neurons was demonstrated. Oil red $\mathrm{O}$ stain of fresh frozen sections of the hippocampus and temporal neocortex in Case 1 and the temporal and frontal neocortices of Case 2 both showed excessive lipid within the cytoplasm of many neurones that were otherwise preserved (Fig. 4E). Semi-thin sections embedded in epoxy resin and stained with toluidine blue demonstrated vacuolation of the cytoplasm of many neurons (Fig. 4F). Some astrocytes filled with lipid surrounded small cap- illaries, but endothelial cells did not show excess lipid (not illustrated).

\section{Transmission EM}

Transmission EM of the neocortex in the three cases was similar, showing accumulation of large lipid droplets in the cytoplasm of the soma and also the neurites, as well as scattered lipid droplets in the neuropil (Figs. 6-8). The lipid was so extensive in some cells that organelles, microtubules and neurofilaments were difficult to identify, but occasional mitochondria retained well-formed cristae (Fig. 6C). 

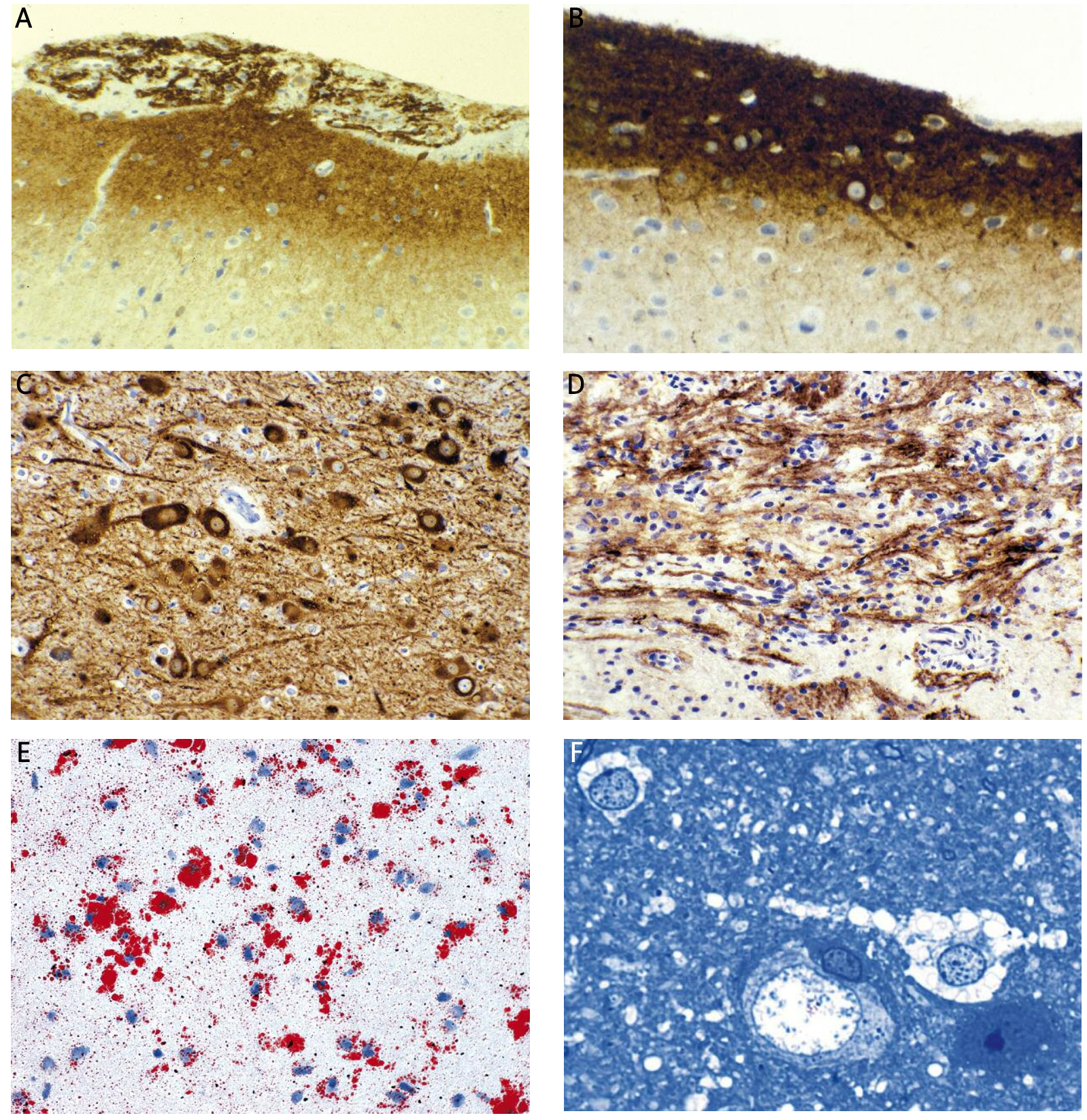

Fig. 4. Case 2. A) $1^{\text {st }}$ surgical resection at age 7 months of temporal neocortex, showing strong tau overexpression, including within a trans-pial pedunculated glioneuronal heterotopion. B-E) $2^{\text {nd }}$ surgical resection at age 18 months, of frontal neocortex, showing (B) strong tau reactivity in the molecular zone and in many neurones and neuropil of layer 2; the architectural lamination of the cortex is disrupted and neurones are disoriented. C) Intense tau expression in seen in disoriented neurons and their processes in the neuropil in a disorganized heterotopion beneath the cortex. D) Tau reactivity is strongly evident in the thickest axons of white matter. E) Oil red $O$ stain of fresh frozen section of temporal neocortex of $1^{\text {st }}$ resection shows many neurones filled with lipid in their cytoplasm. F) Semithin epoxy resin section stained with toluidine blue for light microscopy, of temporal neocortex. A large neurone in the centre exhibits highly vacuolated cytoplasm of the soma and neuritis, likely filled with lipid. Another smaller neurone in the upper left of the panel shows similar lipid droplets filling its somatic cytoplasm. Two other neurones in the lower half of the panel, including one with an adherent satellite glial cell, are not vacuolated. Scattered small lipid droplets are seen in the neuropil throughout. Original magnifications $(A, B) \times 100 ;(C-E) \times 250 ;(F) \times 400$. 


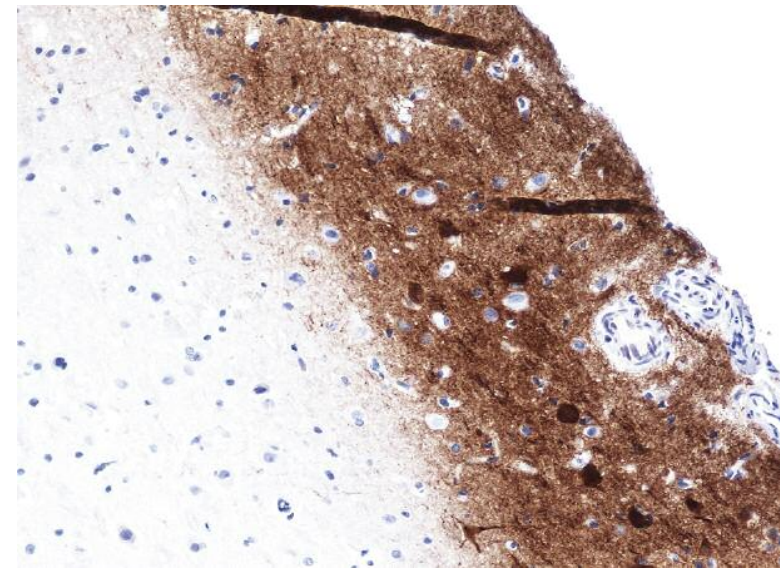

Fig. 5. Case 3. Frontal cortex resected at 2.5 years of age. Strong phosphorylated tau immunoreactivity is expressed in the molecular zone and superficial layers of dysplastic cortex, both in neurones and in processes comprising the neuropil. A focal area of leptomeninges containing small blood vessels invades the cortex, but is non-reactive for tau. Original magnification $\times 250$.

Endothelial cells of parenchymal blood vessels were not altered, but were often surrounded by astrocytic processes that were also filled with lipid droplets (Fig. 6D). Bi-nucleated neurones were identified in places, as well as other atypical morphological forms. The lipid was more extensive in dysmorphic neurones than in the morphologically more normal cells, but the quantity varied from neurone to neurone, even within the same field. Scattered balloon cells did not store lipid in their cytoplasm.

In Case 1, the hippocampus of the hemimegalencephalic left hemisphere confirmed the histochemical findings of excessive lipid storage within neuronal cytoplasm, as well as in proximal segments of neurites. This lipid storage involved some neurones more than others. Neurones of the dentate gyrus did not exhibit the same lipidosis, and neurones of the neocortex showed some lipid, but less than the pyramidal cells of Ammon's horn in their somata and proximal neurites. In the neocortex of both cases, neocortical neurons showed similar findings of lipid storage as was seen in Ammon's horn (Figs. 7A-E). The lipid droplets were present not only in the soma but also extended into the dendritic trunk and proximal axonal segment (Fig. 7E). Scattered degenerating neurons without lipid were also seen, often associated with well-preserved adherent satellite glial cells. Endothelial cells of parenchymal capillaries had normal ultrastructure, including organelles, and did not exhibit the same lipid storage as seen in neurons. Some glial cells showed cytoplasmic lipid, but smaller in number and in size than in neurones. At times, the lipid filling the cytoplasm posed difficulties in distinguishing neurones from glial cells except by nuclear detail and morphology of their cellular processes. Satellite glial cells were not nearly as severely involved as the neurones to which they were adherent. Centrosomes were not identified in any cells.

Tissue preservation for EM was excellent except in Case 3 because of delay in fixation. Nevertheless, many atypical or dysplastic neurones or cells of uncertain neuronal/glial lineage were identified in frontal neocortex, that had well-preserved mitochondria and granular endoplasmic reticulum, but that also exhibited multiple cytoplasmic lipid droplets of variable electron density (not shown). Plasma and nuclear membranes were well preserved.

\section{mTOR markers}

Our HME cases 1 and 2 revealed evidence of mTOR hyperactivation, as demonstrated by immunoreactivity for phospho-4E-BP1 and phospho-ribosomal S6 proteins especially in cytomegalic and dysplastic neurones (Fig. 8). Suitable tissue was not available for this tudy from Case 3. These phospho-isoforms are downstream substrates of mTORC1 and are robustly expressed in specimens of postnatal HME $[1,9,10,20]$. Cells that showed mTOR activation were the dysplastic neurons that also exhibited tau overexpression, hence the two techniques were generally congruent.

\section{Other malformations}

Excessive tau immunoreactivity was not identified in the neocortex or hippocampus of infants with other malformations except in cortical tubers, but tau reactivity was less intense in tuberous sclerosis than in HME. Amongst mitochondrial encephalopathies, we previously reported the absence of tau in a case of Alpers disease with a POLG1 mutation with abnormal lipid metabolism [24] and anecdotally we assert a lack of tau over-expression in two other cases of infantile mitochondrial cytopathy.

\section{Discussion}

\section{Tau and microtubular function}

Tauopathies in foetal life or early postnatal life have not been previously described. Nonetheless, excessive 

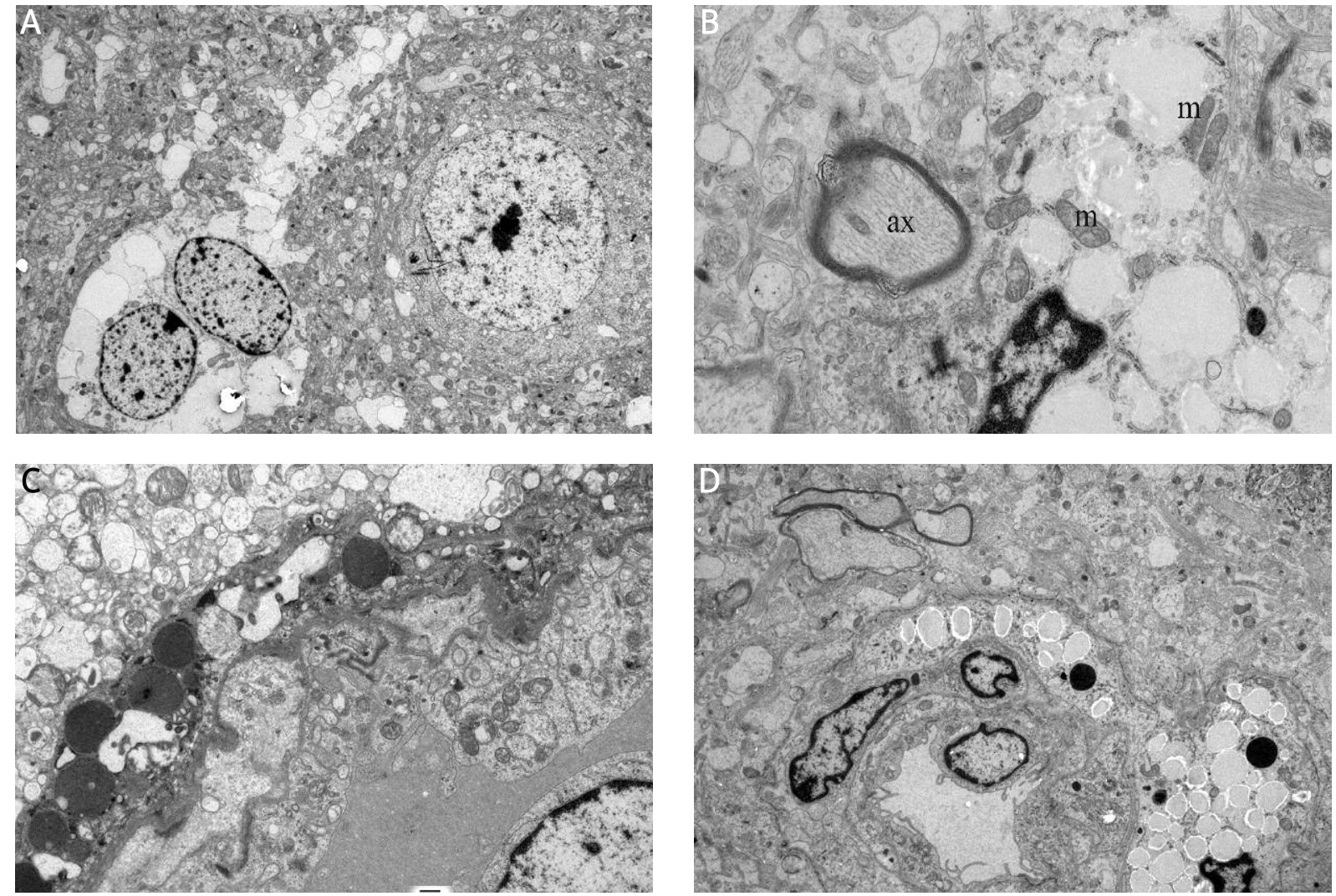

Fig. 6. Case 1. A) Ultrastructure of two neural cells in the left temporal neocortex in the hemimegalencephalic hemisphere. The dysplastic, bi-nucleated cell on the left is filled with coarse lipid filling the cytoplasm that extends into the basal dendrite and resembling vacuoles, but degeneration or death are not evident; the identity of this dysmorphic cell as a neurone or astrocyte is uncertain. The more normal-appearing neurone on the right has only a few small droplets in the periphery and organelles are well preserved, including granular endoplasmic reticulum and mitochondria. B) Dysplastic subcortical heterotopic neurone filled with lipid that obscures many organelles, but mitochondria $(\mathrm{m})$ are still identified and have well-preserved cristae. Axons (ax) of passage in the surrounding white matter contain normal neurofilaments and no lipid droplets, but myelin sheaths are thinner than expected. C, D) Endothelial cells of two parenchymal capillaries are not altered and do not store lipid, but coarse astrocytic processes or end-feet that surround the capillary, as part of the blood-brain barrier, are filled with lipid droplets. Mitochondria exhibit well-preserved cristae. Transmission electron microscopy. Osmium tetroxide, uranyl acetate and lead citrate.

tau upregulation in the developing brain, even in the non-phosphorylated natural form, would be more likely to interfere with ontogenetic processes than to present as a degenerative disease as it does in the mature brain. Hyperphosphorylated tau is now described not only in the elderly but also in young adults with a clinical neurodegenerative course [14]. Neurones of the locus coeruleus also over-express tau in these young patients [14], but not in our infantile Case 1 of HME. Microtubule-based impaired transport is already implicated in the pathogenesis of several genetic cortical malformations, such as the lissencephalies [31].
Mutations in the K1F7 gene recently have been shown to link Joubert syndrome, involving aplasia of the posterior cerebellar vermis and midbrain dysgenesis, with abnormal microtubular dynamics that also involve Sonic hedgehog signalling and a putative ciliary motor protein [12]. Primary cilia are defective in many brain malformations. Microtubules are primordial in early cellular differentiation, including lineage. They are ancient in cellular evolution and form the strands of the mitotic spindle; ancestral microtubules are long spiral protein chains, the "proto-tubulins" synthesized in bacteria [38]. The implication of primitive microtubules in 

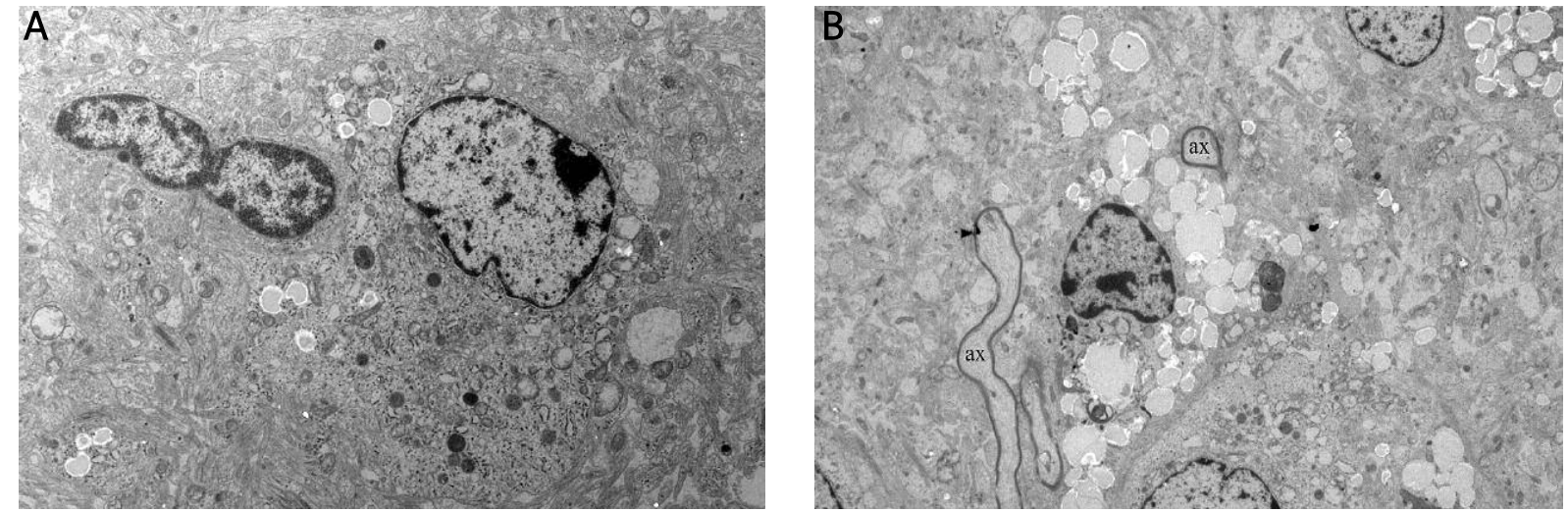

Fig. 7. Case 2. A) Ultrastructure of a neurone of the left temporal neocortex in the hemimegalencephalic hemisphere exhibits only a few small lipid droplets within its somatic cytoplasm and extending into neurites. Organelles, including granular endoplasmic reticulum, mitochondria, free ribosomes and neurofilaments are well defined and appear normal. A satellite glial cell with a mildly dysmorphic bilobular nucleus is seen on the left, adherent to this neurone. Scattered lipid droplets are seen in the neuropil within neuritis. B) A large pyramidal neurone exhibits most of its somatic cytoplasmic volume filled with coarse lipid droplets that extend into the basal dendrite and axon, obscuring cytoplasmic organelles. Smaller axons in the neuropil (ax) have disproportionately thin myelin sheaths, a characteristic finding in HME. A, B) Transmission electron microscopy. Osmium tetroxide, uranyl acetate and lead citrate.

the pathogenesis of hamartomatous malformations such as HME thus is a plausible hypothesis; abnormal microtubule-associated proteins such as tau may cause abnormal function during cellular differentiation, yielding a very different clinical expression in the embryo and foetus than one would expect in the adult brain exposed to the deleterious effects of MAP proteins on previously well-formed microtubules.

In the normal mature brain, six tau isoforms are generated by alternative splicing of pre-mRNA [25]. Two functionally distinct groups are recognized in accordance with the number of microtubule-binding domains they contain: 3-repeat tau (3R-tau) and 4-repeat tau (4R-tau), which normally are equal in ratio [21]. Tau binding to microtubules and plasma membrane is determined by phosphorylation, the higher the phosphorylation the weaker the binding [33]. It is phosphorylated tau that causes the disintegration of microtubules in adult neurodegenerative diseases, which also impairs the functions of normal tau that promote assembly and stability of microtubules [8,21]. It is misfolding of the tau protein induced by phosphorylation that is the basis of structurally modified tau molecules that function defectively [50]. Tau is particularly expressed in glial cells in white matter, both astrocytes and oligodendrocytes, though neurones can also exhibit tau overexpression in their cytoplasm. The monoclonal tau anti- body used for immunoreactivity in our study was a mildly phosphorylated form that is strongly over-expressed in many adult neurodegenerative diseases. In this present study we did not attempt to individually examine the various forms of phosphorylated tau expressed in our cases, but this approach, as well as Western blot analysis, is the next logical step in defining HME as a tauopathy.

Over-expression of tau protein in these cases was largely confined to the hamartomatous malformation, but was also found focally expressed in the contralateral hemisphere in rare scattered dysmorphic neurones (Fig. 3C). The notable exception of intense tau expression of the right (non-HME) hemisphere of our Case 1 was the cingulate gyrus, (Fig. 3D) in the surgical biopsy taken at age 3 weeks at the time of the corpus callosotomy and reconfirmed postmortem. In addition, this gyrus also showed architectural abnormalities as radial columnar architecture corresponding to focal cortical dysplasia type la in the new scheme of the International League Against Epilepsy [3]. This finding indicates that the genetic gradient of HME at times crosses the midline to involve at least the medial side of the contralateral hemisphere. Phosphorylated tau was not expressed in the brainstem or cerebellum, but none of our cases exhibited hemihypertrophy of posterior fossa structures as occurs in "total HME" and it remains 

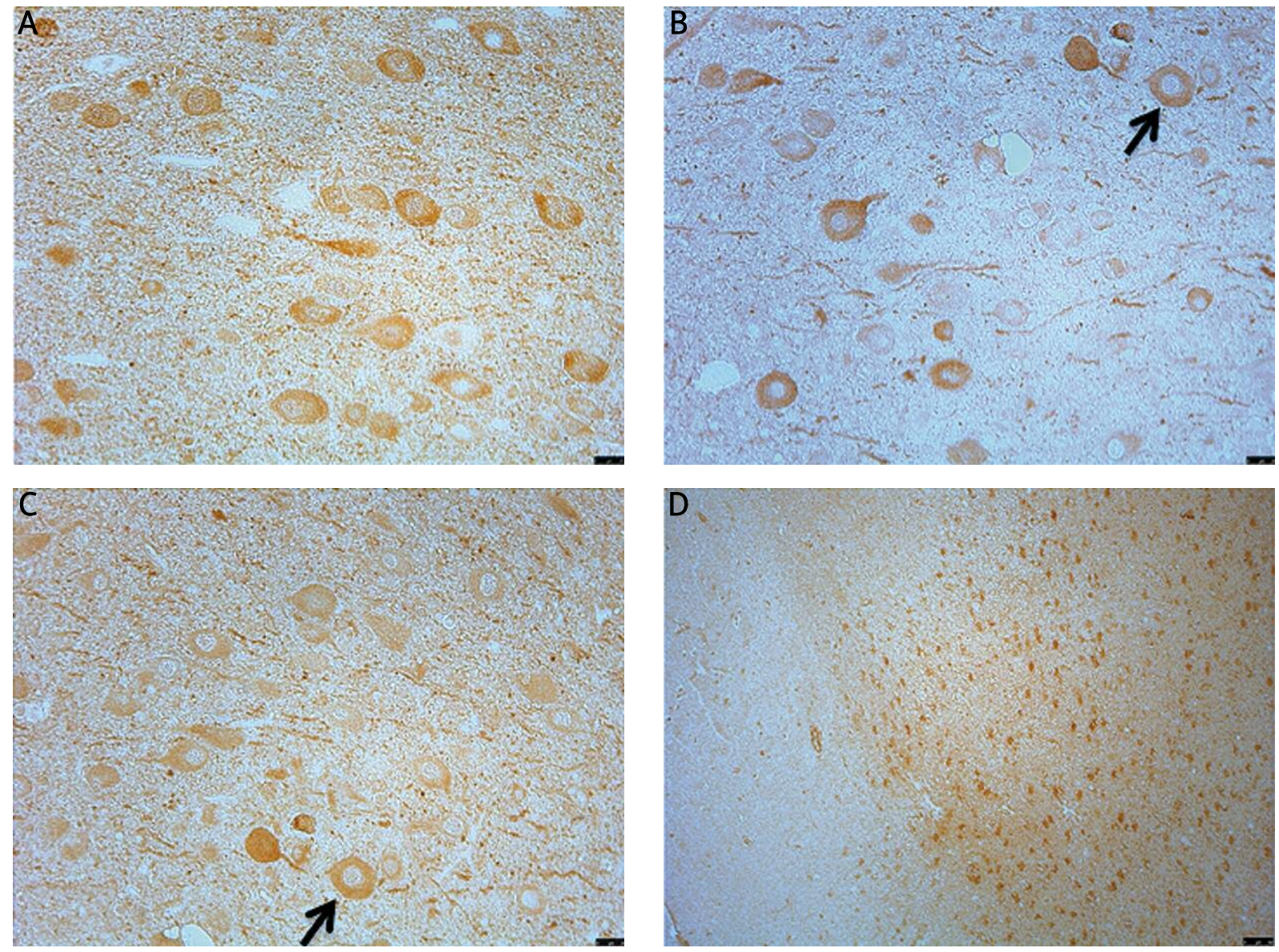

Fig. 8. Case 1. Temporal neocortex of surgical resection of hemimegalencephalic left hemisphere. Phosphoribosomal S6 and phospho-4E-BP1 proteins in a specimen of hemimegalencephaly. A), B) and D) (low magnification) depict phospho-ribosomal S6 protein in balloon cells. Arrow in (B) is the same cell as in (C), exhibiting phospho-4E-BP1 expression. Phosphorylation of S6 and 4E-BP1 is the marker of mTORC1 activation. Similar results were demonstrated in Case 2 (not illustrated).

uncertain whether an enlarged hemicerebellum might show over-expression of phosphorylated tau as well. In adults with early-onset familial Alzheimer disease due to a presenilin-1 mutation, phosphorylated tau is expressed in the cerebellum as well as in the cerebrum [43].

MAP-2, another microtubular protein, strongly expressed in granular cells of the dentate gyrus, pyramidal neurons of Ammon's horn and all neurons of the neocortex, including atypical dysmorphic neurones, in our Case 1 (Fig. 2A). MAP-2 expression is enhanced in the large neurons of focal cortical dysplasias, in the soma and proximal neurites, as demonstrated by immunoreactivity and in situ hybridization with antitense riboprobe, suggesting a microtubular disturbance in the cytoskeleton of these dysplastic cells [46].
MAP-1 and MAP-2 are also impaired by phosphorylated tau [21]. Phosphorylated tau appears to be important in the pathogenesis of HME.

The human tau locus lies on 17q21 and consists of 16 exons spanning $135 \mathrm{~kb}$. Alternative splicing of exon 10 leads to a protein containing either three (3R; exon 10-) or four (4R; exon 10+) tandem repeats of a microtubule-binding motif. The regulation of exon 10 splicing control may underlie susceptibility to disease [28]. Whether over-expression was primary as a genetic mutation of the tau gene [25] or was a secondary reactive phenomenon is uncertain at this time. The monoclonal antibody we used against the phosphorylated form of tau is not found in normal brain in adults or in immature brain during development. Whereas tauopathies in adults represent several different diseases, 
each with distinct clinical and neuropathological features, it is suggested that the overlap actually may be different phenotypes of a similar disease process [4]. Perhaps our foetal/infantile tauopathy here described is yet another part of this spectrum. Genetic studies eventually may confirm or refute this hypothesis. Whether our three cases here reported are representative of all cases of HME or only of a subset is uncertain.

The neuropathological character of phosphorylated tau in our cases of HME is different from the tau expressed in adult neurodegenerative diseases. In the latter, the tau appears as crescent-shaped structures in the cytoplasm of the neuronal and some glial somata, but the intense white matter axonal immunoreactivity with beaded neurites is not characteristic [26]. However, the neocortical layer of most severe neuronal loss and in adult tauopathies is layer 2 [34] and the phosphorylated tau expression in all of our infantile cases of HME was also in the superficial laminae of the cortex, showing a similar gradient within the cortex. Tau over-expression is not specific to HME in paediatric brain tissue, but the only other malformations which share this feature, to our knowledge, are tuberous sclerosis and focal cortical dysplasia type Ilb, with balloon cells and dysplastic neurons, which also share the same property of mTOR activation $[40,49]$. Tau over-expression is also reported many years following traumatic contusions of the brain [22]. Phosphorylated tau can now even be demonstrated and measured in cerebrospinal fluid of adults with normal pressure hydrocephalus and in dementia tauopathies as a clinical marker of prognosis for dementia and gait impairment [23,37].

\section{mTOR}

Hyperactivated mTOR has been identified in HME previously $[1,9,10,20]$ and follows the pattern of tau expression with numerous dysmorphic cells exhibiting phospho-4E-BP1 and phospho-ribosomal S6 protein expression, whereas the contralateral hemisphere does not exhibit these mTOR biomarkers. The identification of enhanced mTOR signalling in the enlarged hemisphere in HME suggests a pathogenetic link between HME and other developmental brain malformations, such as focal cortical dysplasia Ilb, cortical tubers and ganglioglioma. These disorders are all characterized not only by disorganized cortical architecture, but by cytological dysplasia as well and are highly epileptogenic. The finding of phosphorylated tau expression by immunoreactivity in brain tissue of tuberous sclerosis, focal cortical dysplasia IIb and ganglioglioma further reinforces the hypothesis of a common link amongst these diverse disorders [10]. mTOR pathway signalling has been implicated in tau phosphorylation via GSK3 $\beta$ and in cytoskeletal assembly, in particular microtubules via mTORC2 and actin via mTORC1. Indeed HME is reported in association with mutations in known mTOR regulatory genes such as TSC1, TSC2 and PTEN, suggesting that hyperactive mTOR cascade signalling may play a pivotal role in progressive enlargement of one cerebral hemisphere during brain development.

\section{Genetic mechanisms}

The AKT family of genes (also known as protein kinase $\mathrm{B}$; the name does not denote function: $A K$ was a temporary classification name for a strain of mice and $T$ refers to thymoma for an initial investigation) are now strongly implicated as the aetiologies of both Proteus syndrome (AKT1) [30] and HME with or without syndromic associations (AKT3) [29,39]. The close relation of these two genes may explain the association of $\mathrm{HME}$ with Proteus syndrome in our Case 2, an association previously shown clinically in other patients. AKT1 blocks apoptosis and promotes cellular growth and survival, consistent with a role in Proteus syndrome and in HME. AKT3 is less widespread in body organs than $A K T 1$ and is mainly expressed in the nervous system. Mice lacking AKT3 have small brains [47]. Genetic studies of frozen brain tissue are currently in progress from our Cases 1 and 2, and of blood in Case 2.

Of relevance to the present findings is that $A K T$ is involved in the mTOR signalling pathway [29] and also the demonstration that the $A K T$ family in rodents co-regulates tau degradation through co-ordinated interactions with another cytosolic chaperone, tau ubiquitin ligase (CHIP), both dependent upon heat shock protein HSP-90 [13]. This association could also explain in part the over-expression of $\alpha$-B-crystallin in our cases of HME, as this small heat shock protein is very similar to HSP-27, though $\alpha$-B-crystallin is over-expressed as well at epileptogenic foci in patients without HME [41].

\section{Lipidosis}

The lipid storage in pyramidal neurones of Ammon's horn and neocortex in the involved HME hemi- 
sphere, was demonstrated by light microscopy in neurones and some glial cells by oil red $\mathrm{O}$ histochemistry and as vacuoles in the semi-thin sections in epoxy resin, and confirmed by electron microscopy. This lipid suggests impaired utilization of substrate, though we do not presently have evidence of a specific enzymatic deficiency or other defect in lipid metabolism. Mitochondria had well-formed cristae and exhibited none of the ultrastructural abnormalities associated with mitochondrial cytopathies and other clinical and pathological findings of mitochondrial cytopathy were also absent. The microtubules and endoplasmic reticulum in the cytoplasm of most neuronal somata and their neurites were poorly visualised because the coarse lipid droplets obscured them and most of the neurofilaments, but a few preserved microtubules, were seen in neurons with less lipid accumulation. Many neurones of Ammon's horn showed increased histochemical activity of mitochondrial respiratory chain enzymes suggestive of a hypermetabolic state, but this finding is seen as well in epileptic foci of otherwise normal children [42]. The significance of the lipid droplets in pyramidal cells of Ammon's horn and neurones in all layers of the neocortex remains unknown. In our cases of HME we did not find the fine filamentous ultrastructure of neuronal "inclusions" usually seen in adult neurodegenerative tauopathies and neuronal lipid storage is not a characteristic feature of these adult diseases [11]. The lipid storage in the brain was similar in all our HME cases, with or without an associated epidermal nevus syndrome. This common feature suggests that there may be a similar metabolic defect in the dysplastic brain tissue in isolated and associated forms of HME. "Dysregulated adipose tissue" is a characteristic feature in Proteus syndrome [6, 7] and our Case 2 has somatic overgrowth features of this disorder in addition to epidermal naevus syndrome.

One of the striking features in the EM was lipid storage not only in many scattered neurones of the cortex and subcortical white matter, but also of astrocytes with coarse processes and end-feet adherent to the external surface of the endothelium of parenchymal capillaries (Figs. 6C, D). Astrocytic end-feet are an important component of the blood-brain barrier, and impaired transport of nutrients, gases and products of metabolism may contribute to neurological dysfunction in children with HME.

\section{Therapeutic implications}

Everolimus (rapamycin) is an inhibitor of the mTOR pathway shown in humans to diminish the size of subependymal giant cell astrocytomas and also cortical tubers in tuberous sclerosis $[27,35,45]$. Because HME is another malformation involving the mTOR pathway, everolimus might also be effective. Prenatal diagnosis of HME is possible by foetal MRI (e.g. our Case 2) and everolimus might reduce the postnatal neurological morbidity of HME, including epilepsy. The evidence presented here helps to justify clinical trials of perinatally diagnosed $\mathrm{HME}$.

\section{Acknowledgments}

We are grateful to Dr Arthur Clark, Section of Neuropathology, University of Calgary, for reviewing the immunocytochemistry and offering helpful comments in comparing our cases with adult tauopathies. Dr Christopher Dunham, Section of Neuropathology, University of British Columbia, provided the cases of anencephaly. We thank Gaston Guenette and Patricia McInnis of the Histopathology Laboratory at Alberta Children's Hospital, and Vivian King and her staff in the Immunopathology Laboratory of Calgary Laboratory Services, for their technical preparation of tissues. We are also indebted to Ms Elaine Yung and Mr Weyman Chan of Calgary Laboratory Services for their meticulous technical support in the preparation of the tissues and assistance for the EM studies. Ms Marianna Baybis performed the mTOR biomarker assays.

\section{References}

1. Aronica E, Boer K, Baybis M, Yu J, Crino PB. Co-expression of cyclin D1 and phosphorylated ribosomal 56 proteins in hemimegalencephaly. Acta Neuropathol 2007; 114: 287-293.

2. Balaji R, Kesavadas C, Ramachandran K, Nayak SD, Priyakumari T. Longitudinal CT and MR appearances of hemimegalencephaly in a patient with tuberous sclerosis. Child Nerv Syst 2008; 24: 397-401.

3. Blümcke I, Thom M, Aronica E, Armstrong DD, Vinters HV, Palmini A, Jacques TS, Avanzini G, Barkovich AJ, Battaglia G, Becker A, Cepeda C, Cendes F, Colombo N, Crino P, Cross JH, Delalande O, Dubeau F, Duncan J, Guerrini R, Kahane P, Mathern G, Najm I, Ozkara C, Raybaud C, Represa A, Roper SN, Salamon N, Schulze-Bonhage A, Tassi L, Vezzani A, Spreafico R. Special Report: The clinicopathologic spectrum of focal cortical dysplasias: a consensus classification proposed by an ad hoc task force of the ILAE Diagnostic Methods Commission. Epilepsia 2011; 52: 158-174.

4. Bouchard M, Suchowersky O. Tauopathies: one disease or many? Can J Neurol Sci 2011; 38: 547-556. 
5. Bunker J, Wilson L, Jordan M, Feinstein SC. Modulation of microtubule dynamics by tau in living cells: implications for development and neurodegeneration. Mol Biol Cell 2004; 15: 2720-2728.

6. Cohen MM Jr, Neri G, Weksberg R. Overgrowth Syndromes. Oxford University Press, Oxford 2002, pp. 75-110.

7. Cohen MM Jr. Proteus syndrome: an update. Am J Med Genet C Semin Med Genet 2005; 137C: 38-52.

8. Cowan CM, Bossing T, Page A, Shepherd D, Mudher A. Soluble hyper-phosphorylated tau causes microtubule breakdown and functionally compromises normal tau in vivo. Acta Neuropathol 2010; 120: 593-604.

9. Crino PB. Molecular pathogenesis of focal cortical dysplasia and hemimegalencephaly. J Child Neurol 2005; 20: 330-336.

10. Crino PB. Focal brain malformations: seizures, signaling, sequencing. Epilepsia 2009; 50 (Suppl 9): 3-8.

11. Crowther RA, Goedert M. Abnormal tau-containing filaments in neurodegenerative diseases. J Struct Biol 2000; 130: 271-279.

12. Dafinger C, Liebau MX, Elsayed SM, Hellenbroich Y, Boltshauser E, Korenke GG, Fabretti F, Janecke AR, Ebermann I, Nürnberg G, Nürnberg P, Zentgraf H, Koerber F, Addicks K, Elsobky E, Benzing T, Schermer B, Bolz HJ. Mutations in K1F7 link Joubert syndrome with Sonic hedgehog signaling and microtubule dynamics. I Clin Invest 2011; 121: 2662-2667.

13. Dickey CD, Koren J, Zhang Y-J, Xu Y-F, Jinwal UK, Birnbaum MJ, Monks B, Sun M, Cheng JQ, Patterson C, Bailey RM, Dunmore J, Soresh S, Leon C, Morgan D, Petrucelli L. Akt and CHIP coregulate tau degradation though coordinated interactions. Proc Natl Acad Sci USA 2008; 105: 3622-3627.

14. Elobeid A, Soininen H, Alafuzoff I. Hyperphosphorylated tau in young and middle-aged subjects. Acta Neuropathol 2012; 123: 97-104.

15. Flores-Sarnat L. Hemimegalencephaly: Part 1. Genetic, clinical and imaging aspects. J Child Neurol 2002; 17: 373-384.

16. Flores-Sarnat L. Hemimegalencephaly syndrome. In: Handbook of Clinical Neurology. Vol. 87. Malformations of the Nervous System. Sarnat HB, Curatolo P (eds.). Elsevier, Edinburgh 2008 pp. 153-176.

17. Flores-Sarnat L Epidermal nevus syndrome. In: Handbook of Clinical Neurology, Vol. 111: Pediatric Neurology. Dulac O, Sarnat HB, Lassonde M (eds.). Elsevier, Amsterdam 2012 [in press].

18. Flores-Sarnat L, Sarnat HB, Dávila-Gutiérrez G, Álvarez A. Hemimegalencephaly: Part 2. Neuropathology suggests a disorder of cellular lineage. J Child Neurol 2003; 18: 776-785.

19. Galluzzi P, Cerase A, Strambi M, Buoni S, Fois A, Venturi C. Hemimegalencephaly in tuberous sclerosis complex. J Child Neurol 2002; 17: 677-680.

20. Goedert M, Spillantini M, Potier M, Ulrich J, Crowther RA. Cloning and sequencing of the CDNA encoding an isoform of microtubuleassociated protein tau containing four tandem repeats: differential expression of tau protein mRNAs in human brain. EMBO J 1989; 8: 393-399

21. Iqbal K, Liu F, Gong C-X, Alonso Adel C, Grundke-lqbal I. Mechanisms of tau-induced neurodegeneration. Acta Neuropathol 2009; 118: 53-69.

22. Johnson VE, Stewart W, Smith DH. Widespread tau and amyloidbeta pathology many years after a single traumatic brain injury in humans. Brain Pathol 2012; 22: 142-149.
23. Kang JH, Vaanderstichele H, Trojanowski JQ, Shaw LM. Simultaneous analysis of cerebrospinal fluid biomarkers using microsphere-based XMAP multiplex technology for early detection of Alzheimer's disease. Methods 2012; 56: 484-493.

24. Khan A, Trevenen C, Sarnat HB, Payne E, Kirton A. Alpers syndrome: the natural history of a case highlighting neuroimaging, neuropathology, and fat metabolism. J Child Neurol 2012; 27: 636-640.

25. Kovacs GG, Budka H. Current concepts of neuropathological diagnostics in practice: neurodegenerative diseases. Clin Neuropathol 2010; 29: 271-288.

26. Kovacs GC, Rozemuller AJ, van Swieten JC, Gelpi E, Majtenyi K, Al-Sarraj S, Troakes C, Bódi I, King A, Hortobágyi T, Esiri MM, Ansorge O, Giaccone G, Ferrer I, Arzberger T, Bogdanovic N, Nilsson T, Leisser I, Alafuzoff I, Ironside JW, Kretzschmar H, Budka H. Neuropathology of the hippocampus in FTLD-Tau with Pick bodies: a study of the BrainNet Europe Consortium. Neuropathol Appl Neurobiol 2012; doi: 10.1111/j.1365-2990.2012.01272.x. [Epub ahead of print].

27. Krueger DA, Care MM, Holland K, Agricola K, Tudor C, Mangeshlear P, Wilson KA, Byars A, Sahmoud T, Franz DN. Everolimus for subependymal giant cell astrocytomas in tuberous sclerosis. N Engl J Med 2010; 363: 1801-1811.

28. Lawler SE, Senior S, Ingelsson M, Saeki Y, Hyman BT, Monaco E, Chiocca A, Wade-Martins R. The HSV-1 iBAC amplicon vector for functional genomics studies into the genetic mechanisms of neurodegenerative disease. Mol Therapy 2004; 9: S301-S302.

29. Lee JH, Huynh M, Silhavy JL, Kim S, Dixon-Salazar T, Heiberg A, Scott E, Bafna V, Hill KJ, Collazo A, Funari V, Russ C, Gabriel SB, Mathern GW, Gleeson JG. De novo somatic mutations in components of the P13K-AKT3-mTOR pathway cause hemimegalencephaly. Nat Genet 2012; 44: 941-945.

30. Lindhurst MJ, Sapp JC, Teer JK, Johnston JJ, Finn EM, Peters K, Turner J, Cannons JL, Bick D, Blakemore L, Blumhorst C, Brockmann K, Calder P, Cherman N, Deardorff MA, Everman DB, Golas G, Greenstein RM, Kato BM, Keppler-Noreuil KM, Kuznetsov SA, Miyamoto RT, Newman K, Ng D, O'Brien K, Rothenberg S, Schwartzentruber DJ, Singhal V, Tirabosco R, Upton J, Wientroub S, Zackai EH, Hoag K, Whitewood-Neal T, Robey PG, Schwartzberg PL, Darling TN, Tosi LL, Mullikin JC, Biesecker LG. A mosaic actaivating mutation in AKT1 associated with Proteus syndrome. N Engl J Med 2011; 365 : 611-619.

31. Liu JS, Walsh CA. Rare genetic causes of lissencephaly may implicate microtubule-based transport in the pathogenesis of cortical dysplasias. Epilepsia 2010; 51 (suppl 5): 67; also in Jasper's Basic Mechanisms of the Epilepsies. $4^{\text {th }}$ ed. Noebels JL, Avoli IM, Rogawski MA, Olsen RW, Delgado-Escueta AV (eds.). Oxford University Press, New York 2010.

32. Lowe J, Mirra SS, Hyman BT, Dickson DW. Ageing and dementia. In: Greenfield's Neuropathology. $8^{\text {th }}$ ed. Love S, Louis DN, Ellison DW (eds.). Hodder Arnold L, London 2008; 1: 1031-1152.

33. Maas T, Eidenmüller J, Brandt R. Interaction of tau with the neural membrane cortex is regulated by phosphorylation at sites that are modified in paired helical filaments. J Biol Chem 2000; 275 : 15733-15740.

34. Mackenzie IR, Neumann M, Cairns NJ, Muñoz DG, Isaacs AM. Novel types of frontotemporal lobar degeneration: beyond tau and TDP-43. J Mol Neurosci 2012; 122: 87-89. 
35. Major P. Potential of mTOR inhibitor for the treatment of subependymal giant cell astrocytomas in tuberous sclerosis complex. Aging 2011; 3: 189-191.

36. O'Kusky JR, Akers M-A, Vinters HV. Synaptogenesis in hemimegalencephaly: The numerical density of asymmetric and symmetric synapses in the cerebral cortex. Acta Neuropathol 1996; 92: 156-163.

37. Patel S, Lee EB, Xie SX, Law A, Jackson EM, Arnold SE, Clark CM, Shaw LM, Grady MS, Trojanowski JQ, Hamilton RH. Phosphorylated tau/amyloid beta 1-42 ratio in ventricular cerebrospinal fluid reflects outcome in idiopathic normal pressure hydrocephalus. Fluids Barriers CNS 2012; 9: 7.

38. Pilhofer M, Ladinsky MS, McDowall AW, Petroni G, Jensen GJ. Microtubules in bacteria: ancient tubulins build a five-protofilament homolog of the eukaryotic cytoskeleton. PLoS Biol 2011; 9: e1001213.

39. Poduri A, Evrony GD, Cai X, Elhosary PC, Beroukhim R, Lehtinen MK, Hills LB, Heinzen EL, Hill A, Hill RS, Barry BJ, Bourgeois BF, Riviello J, Barkovich AJ, Black PM, Ligon KL, Walsh CA. Somatic activation of AKT3 causes hemispheric brain malformations. Neuron 2012; 74: 41-48.

40. Roberson EK, Hope OA, Martin RC, Schmidt D. Geriatric epilepsy: research and clinical directions for the future. Epil Behav 2011; 22 103-111.

41. Sarnat HB, Flores-Sarnat L $\alpha$-B-crystallin as a tissue marker of epileptic foci in paediatric resections. Can J Neurol Sci 2009; 36: 566-574.

42. Sarnat HB, Flores-Sarnat L, Hader W, Bello-Espinosa L. Mitochondrial "hypermetabolic" neurons in paediatric epileptic foci. Can J Neurol Sci 2011; 38: 909-917.

43. Sepulveda-Falla D, Matschke J, Bernreuther C, Hagel C, Puig B, Villegas A, Garcia G, Zea J, Gomez-Mancilla B, Ferrer I, Lopera F, Glatzel M. Deposition of hyperphosphorylated tau in cerebellum of PS1 E280A Alzheimer's disease. Brain Pathol 2011; 21: 452-463.

44. Takashima S, Chan F, Becker LE, Kuruta H. Aberrant neuronal development in hemimegalencephaly: immunohistochemical and Golgi studies. Pediatr Neurol 1991; 7: 275-280.

45. Yalon M, Ben-Sira L, Constantini S, Toren A. Regression of subependymal giant cell astrocytomas with RAD001 (Everolimus) in tuberous sclerosis complex. Child's Nerv Syst 2011; 27: 179-181.

46. Yamanouchi H, Zhang W, Jay V, Becker LE. Enhanced expression of microtubule-associated protein-2 in large neurons of cortical dysplasia. Ann Neurol 1996; 39: 57-61.

47. Yang ZZ, Tschopp O, Baudry A, Dümmler B, Hynx D, Hemmings BA. Physiological functions of protein kinase B/Akt. Biochem Soc Trans 2004; 32 (Pt.2): 350-354

48. Yasha TC, Santosh V, Das S, Shankar SK. Hemimegalencephaly: morphological and immunocytochemical study. Clin Neuropathol 1997; 16: 17-22.

49. Xi ZQ, Wang XF, Shu XF, Chen GJ, Xiao F, Sun JJ, Zhu X. Is intractable epilepsy a tauopathy? Med Hypotheses 2011; 76: 897-900.

50. Zilka N, Korenova M, Novak M. Misfolded tau protein and disease modifying pathways in transgenic rodent models of human tauopathies. Acta Neuropathol 2009; 118: 71-86. 